\title{
Control of framed structures using intelligent monitoring networks
}

\author{
Dora Foti $^{1, *}$, Massimo La Scala ${ }^{2}$, Silvia Lamonaca $^{2}$ and Vitantonio Vacca ${ }^{1}$ \\ ${ }^{1}$ Polytechnic University of Bari, Department of Civil Engineering Sciences and Architecture, Via Orabona 4, 70125 Bari, Italy \\ ${ }^{2}$ Polytechnic University of Bari, Department of Electrical and Computer Science Engineering, Via Orabona 4, 70125 Bari, Italy
}

\begin{abstract}
The paper proposes the integration of structural monitoring with Building Management Systems for electricity and gas distributions. To assess the state of damage of existing buildings the technics of Structural Health Monitoring (SHM) is adopted. SHM as well as to record the occurrence of sudden structural damage resulting from exceptional events (earthquakes, explosions, shocks and collisions with vehicles, etc.), allows the monitoring of the progressive damage and structural performance under operating conditions through the extraction of the modal parameters of the structure. This approach requires time to process acquired data that, depending on the size of the building and the number of monitored points, varies from minutes to hours. In this paper, an intelligent system is proposed to immediately communicate during an earthquake the overrun of a certain ground shaking threshold so that gas delivery and selected power loads are interrupted, as suggested by current national regulations on structures. The use of low-cost and reduced size accelerometric sensors integrated with Energy Monitoring Systems is proposed in both highrisk earthquake centers and in all "strategic" buildings that must ensure their operation use immediately after the earthquake. The procedure for calibrating the horizontal and vertical acceleration threshold is also sketched.
\end{abstract}

\section{Introduction}

In the last two decades, a revolution occurred in the energy sector. Energy systems moved from "operationcentric" grids to "customer-centric" ones, where the final users aim to become independent of the main distribution grid and act as a "prosumer" i.e. a producer and consumer of electricity, heat/cool, and more recently of natural gas or biogas, too. Nowadays, the technology shows the promise to overcome the many technical issues involved in this approach. Furthermore, distributed generation, demand response programs, storage availability and advanced smart metering show the potential to create new business models built around active customers who have reached higher level of awareness and have been enabled to participate directly in the management of energy grids [1-2]. In such scenario, Demand Response (DR) programs constitute the main economical driving force that can break the inherent inelasticity that characterizes end-users energy behaviour, pushing them towards the achievement of higher efficiency goals in the energy use.

This is not the only revolution occurring in this field. Since advanced and evolutionary monitoring systems are implemented in this "customer-centric" transition, it has been realized that the developed applications can handle functions besides the energy- related ones. As an example, these systems can be used for security and safety purposes, surveillance, senior citizen monitoring, anti-intrusion, civil protection, etc.

In this paper, a monitoring system, which can be easily embedded in a Building Energy Monitoring System (BEMS), is presented. The rationale is to use it to gather data about seismic activity and to reduce the earthquakes secondary effects such as fire, explosions, floods. The aim of the paper is to identify a suitable system able to recognize an earthquake and shut down main energy carriers such as electricity and natural gas, avoiding as much as possible false alarms and improper supply interruption. The paper reports some preliminary results obtained through a research activity developed by Polytechnic of Bari and a cluster of firms within the socalled "Energy Router" project and analyses developed in a research project of relevant interest about the mitigation of the impacts of natural hazards and earthquakes.

The interest in this field arises from the fact that Italy is one of the countries in the Mediterranean that most is subject to seismic risk because of its geographic location. The Seismic Hazard Harmonization in Europe (SHARE) project determined the seismicity of the entire European territory and maps have been drawn up in which it is confirmed that Italy, Turkey and Greece are the most threatened seismic areas across Europe (Fig. 1).

Corresponding author: dora.foti@poliba.it 
In recent years, Italy has been affected by a series of seismic events that have interested the territories from North to South causing major damage to construction structures and people (i.e. Central Italy earthquakes: Emilia 2012, Aquila 2009, San Giuliano of Puglia 2002, Umbria-Marche 1997, Irpinia 1980, etc.).

On March $20^{\text {th }} 2003$, the O.P.C.M./3274 code [3] "First Elements on General Criteria for Seismic Classification of National Territories and Technical Standards for Seismic Buildings", was issued. It marked a historic breakthrough at national level for building construction directives. One of the innovations introduced concerns the obligation for designers to analyze not only the structural aspect of the building, but also all the non-structural elements, including at first the life-lines. Over the years it has been possible to see how buildings can withstand seismic action without collapsing, but unfortunately are made unusable due to the damage suffered by life-lines and other elements inserted within the volume. Specifically, in Annex 2 to O.C.M. 3274, the following is stated: "gas installations rated for more than $50 \mathrm{~m}^{3} / \mathrm{h}$ must be equipped with valves for automatic shutdown in case of an earthquake. Gas supply pipes, when moving from the ground to the building, have to be designed to withstand the maximum relative building-ground displacements due to the seismic design action without breaking".

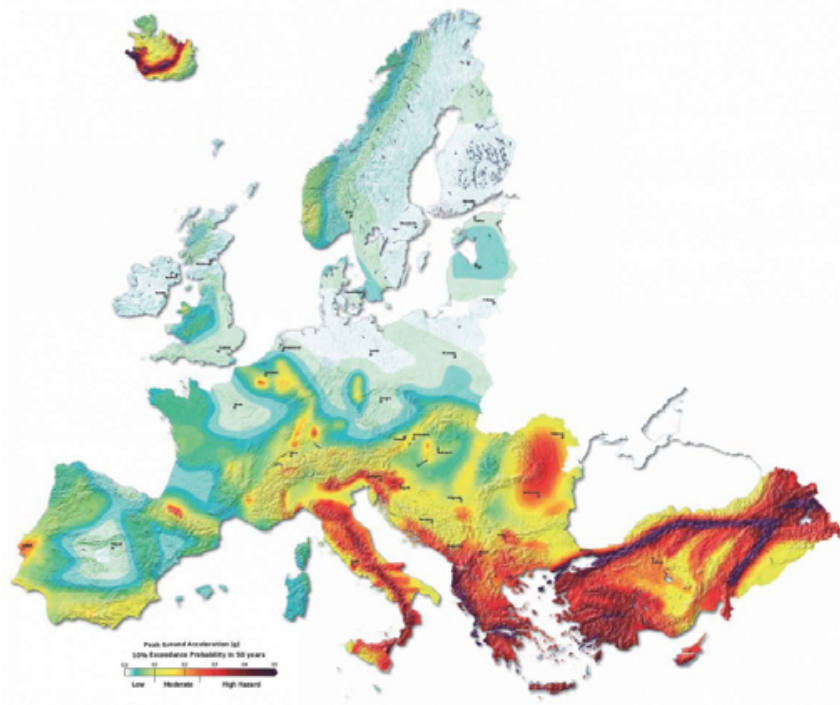

Fig. 1. SHARE Project: Seismic map of Europe: Italy, Greece and Turkey are the countries with higher seismic hazard (PGA with a probability of $10 \%$ to be overcome in 50 years, that is. earthquakes with a return period of 475 years).

It is interesting to note that in OPCM 3274/2003, this obligation was imposed only for life-lines with a gas flow of $50 \mathrm{Nm}^{3} / \mathrm{h}$ or more (corresponding to a power of approximately 400 to $500 \mathrm{~kW}$ ), while during the Legislative updates, and in particular the current NTC 08 $[4,5]$ this limit has been eliminated, leading to intrinsically increasing the safety even for all buildings that do not have large installations. This is of great importance because, while up to a few years ago large buildings required great thermal power, at present, and in light of the international commitments undertaken by Italy, in the years to come we will find buildings with elevate volumes, with high levels of crowding, but with smaller and smaller generators because they are getting less energetic. From these assumptions, it is believed that a conscientious choice has been made and the degree of safety has been increased. In addition in $[4,5]$ it is also specified that the risk of uncontrolled gas leaks should be limited, particularly close to electrical and flammable materials by using breakers.

After about fifteen years, we are aware of a new and profound knowledge of the structural aspect, the effects that an earthquake can cause, and what are the strategies that can be adopted to reduce the risks, but there still does not seem to be full awareness of the strategies, which must be adopted for the protection of non-structural elements and, in particular, systems and technologies for the protection of gas and electricity distribution systems [6].

The aim is to ensure the stability of the life-lines, paying particular attention to the context in which they operate. There are buildings that require special attention and are defined as strategic for which, both during and after the earthquake (hospitals, civil protection coordination centres, firefighters, etc.) their operation must be guaranteed. It is therefore of utmost importance to avoid uncontrolled gas leakage, particularly close to electrical and flammable materials. To do this, it is necessary to adopt automatically interrupting gas distribution devices. Gas supply pipes, from land to construction, must be designed to withstand the maximum relative displacements between the building and the ground without breaking.

Starting from these considerations, we propose a possible, innovative and intelligent automated system for interrupting electricity and gas supply in a building when hit by a disruptive earthquake.

The opportunity is also given by the recent regulation in Italy about the use of smart meters. A massive electricity smart meter deployment occurred in Italy starting from year 2000 (35 million meters installed). Nowadays, the second nation-wide deployment is going on for the installation of a second generation of smart meters linked to optical fibre telecommunication grids (Open Fiber project).

Contemporaneously, a large deployment of gas smart meters has been promoted by the Energy Regulator in Italy ending up in 2018 through the socalled "Directives for the installation of gas smart meters" as modified by the Deliberation of the Autorità Energia Elettrica e Gas 575/2012/R/gas [7]. The installation of an electro-valve remotely controllable is required among minimal features of gas smart meters.

Consequently, the rationale behind the proposed architecture is to use electro-valves available on gas smart meters and electrical switches to interrupt the supply in order to avoid secondary effects due to earthquakes.

\section{Energy Router architecture}

The Energy Router is a hardware/software system for managing and optimizing the complex of input or output 
energy flows from distributed generation devices, storage systems for electricity and user equipment in buildings. Cloud-based software components are adopted for field data analysis and optimization of energy resources. By means of the Energy Router, a small intelligent distribution system, and therefore a small smart grid or a nanogrid at a building or housing level, can be created that can generate an economic benefit for the user in terms of increase in the self-consumption, energy efficiency, renewable productivity, loss reduction, and sales of auxiliary services to the network.

The architecture of the energy router is hybrid and consists of two modules communicating with each other:

- the field section, installed in the building, and designed to control generation, storage and utilization systems, and to control energy flows;

- the cloud section that uses advanced software supervision and control software solutions using forecasting and optimization models that take into account the main input parameters (renewable generation, loads, etc.) and, on the other hand, they permit to optimize the use and management of distributed energy resources (distributed energy resources or DER), while ensuring safe plant management.

The performance that the system assures is related to intelligent energy distribution within the smart grid of the building, optimizing the use of storage systems and ensuring optimum use of the systems in order not to degrade their performance.

The potential of this equipment cannot be confined to the energy sector but it shows the possibility to develop further services for citizens and smart city applications.

Hereby the system is conceived to provide a source of information about seismic activity and control functions to shut down energy services, to eliminate or at least mitigate the secondary effects of earthquakes.

In fact, an additional function of the Energy Router is the management of the gas and power network in the presence of seismic events. The idea is to equip the device with an accelerometer able to detect seismic events and to intervene on the gas network by closing a solenoid valve and switch off power.

In particular, based on numerous studies that have experienced the use of accelerometers typical of electronic devices (smartphones) for detecting seismic events [6], the idea is to install a Micro ElectroMechanical Systems (MEMS) type accelerometer in the Energy Router. Some experiments, for example [8], have shown how the LIS331DLH accelerometer type produced by STMicroelectronics is capable of faithfully recording earthquakes of moderate to severe magnitude.

In general, MEMS accelerometers in the 90s have revolutionized the automotive industry in the airbag industry and are now largely used in laptops, gaming peripherals and mobile phones. Numerous studies have been conducted on MEMS sensors in this field, even in previous years, with appreciable results [9-12]. Thanks to their low cost (few euros) and the small size (few millimeters), they could now be used in earthquake monitoring and alert systems for high-risk earthquake centres.

The device will be sized according to predetermined acceleration ranges, which will require earthquakes with magnitude and intensity of some relevance. The energy router, therefore, detected the hazard signal, will close the user's gas network to which it is connected, by means of a remote controlled solenoid valve. Many of the latest generation gas smart meters are equipped with such solenoid valves, otherwise they may opt for existing commercial systems that can interact with the wireless energy router. The same approach can be more easily applied to switch off power loads characterized by a higher risk to yield short circuits and consequently fires. Power loads linked to the connectivity, i.e. power supply to wireless or telecommunication systems, should not be switched off during earthquakes since experience showed that they resulted very useful to send emergency messages or to localize missing people under ruins.

\section{Monitoring system}

As usual, classical monitoring systems permit to detect the critical structural parameters of the structure (natural oscillation periods and modal shapes) in order to ensure effective maintenance/repair and a high safety standard [13-15]. These systems require a processing time of the acquired data that, depending on the size of the building and the number of monitored points, varies from minutes to hours. It therefore appears evident that the same technology cannot be used for the system proposed here, the objective of which is to immediately communicate during an earthquake the overcoming of a certain ground shaking threshold. Therefore, the field section and the energy cloud section of the energy router must communicate very quickly the order to shut down the gas grid and the power distribution network of the user to which it is connected.

To reach this objective, no checks on the spectral shapes or the contents of the recorded seismic signal (both at the base of the building and at the different levels) can be performed, since this kind of processing requires that all the seismic signal is exhausted [16]. In light of the above, the only control parameters that can be used are the instantaneous values of horizontal and vertical accelerations measured at the foundation's level (Figure 2). This is the only point where a real-time fast comparison can be made between the acceleration values measured by the sensor and those provided by the codes that define the "project earthquake". The structural dynamics on the upper levels depend on many variables that are difficult to evaluate especially for existing buildings: structural typology, materials composing the structure and their mechanical properties, geometry in plan and elevation, local ductility and global structure, distribution and mechanical properties of the partition walls, etc. [17].

The device, integrated into the energy router, will be sized based on predetermined acceleration ranges, which will require magnitude and intensity earthquakes of 
some relevance. Criteria for selection of critical earthquakes are outlined in sect. 3. The energy router, once detected the hazard signal, will then shut down gas distribution and selected power loads.

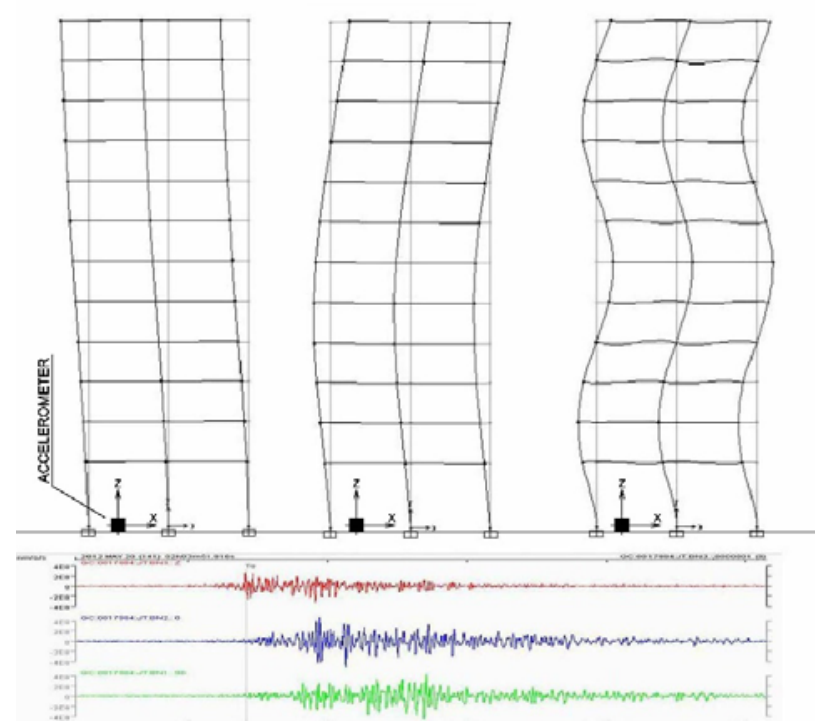

Fig. 2. A triaxial accelerometer must be positioned on the foundation ground of the building for a fast and immediate comparison of the acceleration peaks.

\section{Definition of the vertical horizontal acceleration thresholds}

In the "New Technical Standards for Construction" D.M. Infrastructures 14/01/08 [4], sect. 3, the operational phases to define the design seismic actions to be considered for the design or verification of a building are introduced. These rules apply to both new and existing buildings.

The parameters that permit to deduce the "seismic load" are defined on the basis of a reference grid (Annex B, D.M. 14/01/08), which has been traced on Italian territory with a mesh of about $10 \mathrm{Km}$ and that at each node it matches the values. Starting from the values in the nodes, for each point located on the territory by its geographic coordinates (longitude and latitude), it is possible to detect the seismic hazard parameters for a given return period $T_{R}[4,5]$. The return period is evaluated according to the Reference Life $V_{R}$ function of the building and depending on its overcoming probability $\mathrm{P}_{\mathrm{VR}}$ corresponding to the limit state that has to be analyzed [18]. It is clear from the outset that, for the purposes of this work, the limit state to which reference will be the damage one, that is to say, after an earthquake the construction as a whole, including structural and non-structural elements, equipment relevant to its function, is such that it does not endanger users and does not significantly compromise the strength and stiffness to vertical and horizontal actions, while keeping it in use, even if the equipment is partly interrupted.

Therefore, in order to determine the peak values of the expected horizontal and vertical accelerations to the ground for the Limit State of Damage, the following data are needed, but are easily obtainable:

1 - Municipality in which the building (longitude and latitude) insists;

2- Nominal life of the building (indicated in the structural design of the building);

3- Building Use Class (indicated in the structural design of the building, depending on the consequences of a breakdown of operation or a possible collapse of the building);

4- Stratigraphic and topographic nature of the layout (indicated in the structural design of the building by a coefficient $S$ as defined in point 3.2.3.2.1 NTC-08).

From these, it is possible to obtain the return period TR of the seismic action for the State Limit of Damage, the corresponding horizontal acceleration values of the ground ag and the maximum value of the amplification factor $F_{0}[4,5]$. In Fig. 3, exemplifying, for example, the $a_{g}$ and $F_{0}$ trends as the return period $T_{R}$ varies. In the latter case, it is possible to obtain the values of the maximum horizontal $\mathrm{a}_{\max , \mathrm{O}}$ and vertical $\mathrm{a}_{\max , \mathrm{V}}$ accelerations through the following relationships:

$$
a_{\max , O}=a_{g} S
$$

$$
a_{\max , V}=a_{g} S \cdot 1.35\left(\frac{a_{g}}{g}\right)^{0.5}
$$

where $S$ is the recalled descriptive coefficient of the stratigraphic and topographic nature of the foundation soil.

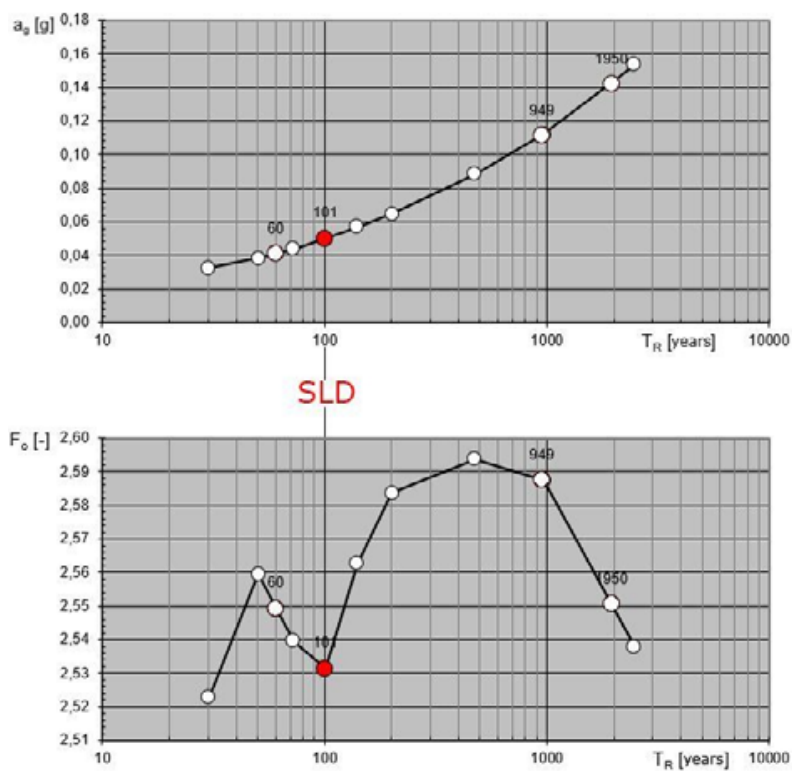

Fig. 3. $a_{g}$ and $F_{0}$ vs. $T_{R}$ (return period) for a building located in Verona (Italy) (long=11.2113; lat=45.193), with a Nominal Life equal to 100 years, Class of use II (constructions with normally crowded so as defined in sect. 2.4.2 NTC -08), foundation ground category of type C (point 3.2.2 NTC-08) and topographic condition T1 (table 3.2.IV NTC-08).

In order to determine the peak acceleration beyond which the system must interrupt the supply of electricity and gas, it must be considered that the horizontal motion 
of the ground occurs at the same time according to the two orthogonal directions $\mathrm{x}$ and $\mathrm{y}$ set by the designer being the direction of the earthquake completely generic. This is taken into account, considering that the, accelerations measured in both directions $X$ and $Y$ at any instant must respect the following ratio:

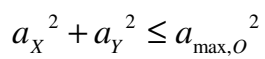

For the vertical acceleration peak, instead, the following expression (4) must be applied:

$$
a_{Z} \leq a_{\max , V}
$$

All of the process described above can be briefly summarized with the block diagram shown in Fig. 4.

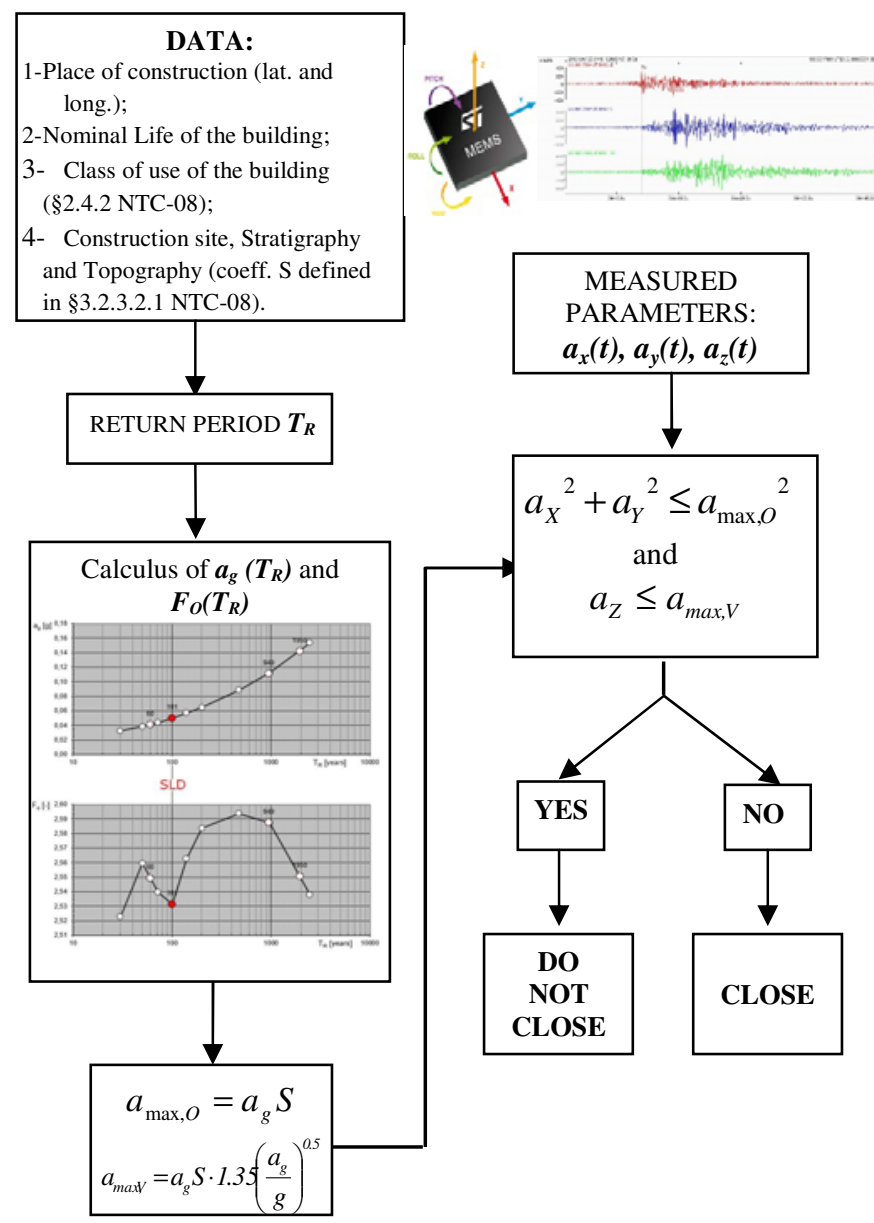

Fig. 4. Process to determine the horizontal and vertical thresholds.

\section{Conclusions}

In the present paper, an intelligent system has been introduced that, through the use of the Energy Router, enables to detect and communicate immediately to the gas and electricity distribution systems the occurrence of an earthquake whose accelerated peak has exceeded a certain threshold, appropriately calibrated. As mentioned in the first section, the existing structural legislation in Italy obliges designers to provide gas valve installations for automatic shutdown in case of earthquake. It is also specified that the risk of uncontrolled gas leaks should be limited, particularly close to electrical and flammable materials, by using breakers.

The system presented here envisages the use of MEMS (Micro Electro-Mechanical Systems) accelerometers typically used in laptops, gaming peripherals and mobile phones which, due to their low cost and small size, could now be used in large-scale earthquake monitoring and alert systems in high seismic areas.

For the field section and the cloud section of the energy router to communicate in real time the possibility of an earthquake and overcoming a certain acceleration threshold to close the gas grid and the power distribution network of the building, it is necessary to measure the horizontal and vertical accelerations at the foundation's level. Structural dynamics in the upper levels depend on many variables that are difficult to assess especially for existing buildings and therefore require a complex and long series of cognitive investigations that would undo the economic benefits of the system here presented.

In this paper is also presented a first algorithm that allows to determine the value of the horizontal and vertical acceleration threshold as a function of few and clear parameters, yet easily found in the structural design:

1. Municipality where the building is located;

2. Use Class of the building;

3. Nominal life of the building;

4. Stratigraphic and topographical nature of the foundation soil.

This procedure permit to personalize the acceleration peaks based on the nature, type and use destination of the building, in extremely fast times and maintaining the same level of reliability in terms of probability of overcoming the "project earthquake".

\section{Acknowledgements}

Massimo La Scala as Principal Investigator of the project "Energy Router" gratefully acknowledge Regione Puglia for funding the project under grant number HX8HXI1 and all the industrial partners participating in the project activities.

Dora Foti as Principal Investigator of the project "Mitigating the impacts of natural hazards on cultural heritage sites, structures and artefacts (MICHe)" acknowledges the Italian Ministry of Education, University and Research for support under a Project of Relevant National Interest PRIN 2015.

\section{References}

1. M. La Scala, S. Bruno, "From Smart Grids to Smart Cities: New Paradigms for Future Networks", introduction to M. La Scala, From Smart Grids to Smart Cities: New Challenges in Optimizing Energy Grids, pp. xvii-xliii, ISTE-Wiley, LondonHoboken(NJ), 2017.

2. S. Bruno, G. Giannoccaro, M. La Scala, Predictive control of demand and storage for residential 
prosumers, to be presented at the $7^{\text {th }}$ IEEE Technologies (IEEE PES ISGT Europe 2017), Turin, Italy, 26-29 September 2017.

3. O.P.C.M. 20/03/2003, n. 3274 (Suppl. Ord. alla G.U. 8.5.2003, N. 105), "Primi elementi in materia di criteri generali per la classificazione sismica del territorio nazionale e normative tecniche per le costruzioni in zona sismica". (in Italian)

4. NTC 2008 - Norme tecniche per le costruzioni D.M. Infrastrutture 14 gennaio 2008. (in Italian)

5. Circolare 2 febbraio 2009, n. 617 (G.U. n. 47 del 262-2009 - Suppl Ord. n. 27) Istruzioni per l'applicazione delle "Nuove norme tecniche per le costruzioni" di cui al D.M. 14 gennaio 2008. (in Italian)

6. M. Cudicio, La protezione sismica degli elementi impiantistici: analisi, strategie, modelli ed esempi applicative. Legislazione tecnica, Ottobre (2014). (in Italian)

7. "Deliberazione 28 Dicembre 2012, 575/2012/R/GAS, Disposizioni in materia di piano di messa in servizio di gruppi di misura elettronici nell'ambito della distribuzione gas", Autorità per l'Energia Elettrica e il Gas. (in Italian)

8. Q. Kong, Y. Kwony, L. Schreierz, S. Allen, R. Allen, J.r Strauss, Smartphone-based networks for earthquake detection, 15th International Conference on Innovations for Community Services (I4CS), (2015).

9. A. D'Alessandro and G. D'Anna, Suitability of LowCost Three-Axis MEMS Accelerometers in StrongMotion Seismology: Tests on the LIS331DLH (iPhone) Accelerometer, Bulletin of the Seismological Society of America, 103, 5, 29062913, October (2013).

10. A. D'Alessandro, D. Luzio, G. D'Anna, Urban MEMS based seismic network for post-earthquakes rapid disaster assessment, Adv. Geosci., 40, 1-9, (2014).
International Conference on Innovative Smart Grid 11. A. D'Alessandro, Monitoring of earthquakes using MEMS sensors, Curr. Sci., 107, 733-734 (2014b).

12. A. Holland, Earthquake Data Recorded by the MEMS Accelerometer: Field Testing in Idaho, Seismological Research Letters, 74, 1, January/February (2003).

13. A. Mufti, Guidelines for Structural Health Monitoring, University of Manitoba, ISIS Canada (2001).

14. A.E. Aktan, S.K. Ciloglu, P.Q. Grimmelsman, F.N. Catbas, Opportunities and challenges in health monitoring of constructed systems by modal analysis, Proc. of the International Conference on Experimental Vibration Analysis for Civil Engineering Structures, Bordeaux, France (2005).

15. D. Foti, M. Diaferio, N.I. Giannoccaro, S. Ivorra, Structural identification and numerical models for slender historical structures. In: p. Asteris \& V.Plevris (Eds.), Handbook of research on Seismic Assessment and Rehabilitation of Historic Structures. Hershey, PA: Eng. Science Reference, Chap 23, pp.674-703 (2015).

16. M. Diaferio, D. Foti, N.I. Giannoccaro, Nondestructive characterization and identification of the modal parameters of an old masonry tower. Proc. EESMS 2014-2014 IEEE Workshop on Environmental, Energy and Structural Monitoring Systems, Naples, Italy, 17-18 September (2014).

17. L. Zhang, R. Brincker, P. Andersen, An Overview of Operational Modal Analysis: Major Development and Issues, Proc. of the 1st IOMAC Conference, Copenhagen, Denmark (2005).

18. C. Rainieri, G. Fabbrocino, E. Cosenza, G. Manfredi, Implementation of OMA procedures using LabView, Proc. of the $2^{\text {nd }}$ IOMAC Conference, Copenhagen, Denmark (2007). 